\title{
¿EXÉGESIS CIENTÍFICA O HERMENÉUTICA TEOLÓGICA? PROBLEMAS DE INTERPRETACIÓN BÍBLICA
}

\author{
Ángel Gómez Navarro*
}

\begin{abstract}
RESUMEN
Se argumenta en torno a la necesidad de recomponer y mantener la unidad de los dos niveles metodológicos del único proceso de interpretación bíblica en la Iglesia, mostrando los elementos científicos y teológicos que configuran esta metodología exegético-hermenéutica. Asimismo, se indican las causas de la separación de dichos niveles y sus respectivas consecuencias que repercuten en la correcta interpretación del mensaje salvífico contenido en los textos bíblicos, así como en nuestra vital relación con la Palabra de Dios, en y desde la comunidad eclesial.
\end{abstract}

PALABRAS CLAVE: Exégesis, hermenéutica, método histórico-crítico, interpretación bíblica

\section{THEOLOGICAL HERMENEUTICS OR SCIENTIFIC EXEGESIS? BIBLICAL INTERPRETATION QUESTIONS}

\begin{abstract}
The article argues for the need to reconstruct the unit of the two methodological levels of the sole biblical interpretation process in the Church, showing the Theological and scientific elements which configure this Exegetical Hermeneutics Methods. Likewise, the causes of the improper separation of such levels and their respective consequences are showed, which seriously affect not only the correct interpretation of the biblical texts, but also our vital relationship with the Word of God, in and from the ecclesiastic community.
\end{abstract}

KEYWORDS: Exegesis, Hermeneutics, critical and historical method, biblical interpretation.

*Doctor y Magíster en Teología por la Pontificia Universidad Gregoriana de Roma. Egresado de la Maestría en Antropología Cultural de la Facultad de Ciencias Sociales de la PUCP. Cursa el Doctorado en Docencia Universitaria e Investigación en la Universidad Marcelino Champagnat. Docente Principal de la Universidad Femenina del Sagrado Corazón y Jefe del Departamento de Filosofía y Teología de la Facultad de Psicología y Humanidades de la misma Universidad. 
La reciente publicación de la Exhortación Apostólica Postsinodal Verbum Domini (VD) de Benedicto XVI, sobre la Palabra de Dios en la Vida y en la Misión de la Iglesia (2010), ha traído nuevamente a colación un tema que es crucial para el ser y quehacer de las comunidades cristianas, me refiero a la relación que debe existir entre la actividad exegética y la hermenéutica teológica, en cuanto niveles metodológicos de un único proceso de interpretación bíblica que busca ayudarnos en nuestra correcta relación con la Palabra de Dios, en y desde la comunidad eclesial.

Con tal documento, no sólo se busca llamar nuestra atención sobre la importancia de captar el verdadero sentido literal y espiritual de los textos bíblicos a partir de una auténtica exégesis teológica, sino también, consolidar el paso de una pastoral bíblica a la animación bíblica de toda la pastoral, que promueva la relevancia histórica y teológica de la Palabra de Dios, pues "la eficacia pastoral de la acción de la Iglesia y de la vida espiritual de los fieles depende en gran parte de la fecunda relación entre exégesis y teología" (VD 31).

La preocupación por esta unidad de la ciencia exegética y la hermenéutica de la fe, ya había sido planteada por la Constitución Dogmática Conciliar sobre la Divina Revelación, Dei Verbum (1963), al afirmar la doble dimensión de la interpretación católica, por la que el intérprete de la Escritura, para conocer lo que Dios quiso comunicarnos, debe estudiar con atención lo que los autores querían decir y Dios quería dar a conocer con dichas palabras" (DV 12).
Por su parte, la Pontificia Comisión Bíblica (PCB), en un documento especial sobre la Interpretación de la Biblia en la Iglesia (IBI) de 1993, también retomó la cuestión subrayando que la tarea común de los exegetas católicos "no está terminada cuando han distinguido fuentes, definido las formas o explicado los procedimientos literarios, sino solamente cuando han iluminado el sentido del texto bíblico como actual Palabra de Dios" (IBI, III, 2, C).

Haciendo un breve recuento histórico sobre el mismo tema, Benedicto XVI cita en su Exhortación, la intervención del Papa León XIII, quien con su encíclica Providentissimus Deus (1893), tuvo el mérito de proteger la interpretación católica de la Biblia de los ataques del racionalismo, pero sin refugiarse en el sentido espiritual o desconectarse de la historia. Más aún, no rechazó la crítica científica sino tan solo cuestionaba las opiniones preconcebidas que pretendían fundarse en la ciencia. Asimismo, cita a Pío XII, quien se enfrentó a los ataques de los defensores de una exégesis espiritualista, que rechazaba cualquier aproximación científica. Con su encíclica Divino afflante Spiritu (1943), Pío XII buscó evitar la dicotomía entre "la exégesis científica" y "la interpretación espiritual", aunque con sesgo apologético. "De este modo, ambos documentos rechazaron 'la ruptura entre lo humano y lo divino, entre la investigación científica y la mirada de fe, y entre el sentido literal y el sentido espiritual" (VD 33).

El carácter unitivo de la metodología exegética teológica tiene su justificación teórica y práctica en el 
hecho de que la Sagrada Escritura es la Palabra de Dios expresada en lenguaje humano. Sin embargo, es aquí donde se ha introducido un peligroso dualismo que ha terminado descomponiendo práctica-mente la unidad requerida en la interpretación bíblica, y al mismo tiempo mostrando, contrariamente, tanto a la exégesis como a la teología como métodos absolutamente irreconciliables.

Esta crisis dicotómica fue evidenciada ya por el entonces Cardenal Ratzinger en una famosa Conferencia pronunciada en Nueva York (1988), sobre "la interpretación bíblica en conflicto", donde puntualizaba, entre otras cosas, que la exégesis crítica, "siguiendo una abundancia de hipótesis cada vez más numerosas,-que finalmente se convierten en una jungla de contradicciones-, no sólo no leen la Biblia sino que la descuartizan en las varias partes de las que ésta habría sido compuesta". En dicha conferencia, se denuncia el intento por suprimir todo residuo no-racional y esclarecerlo todo, excluyendo absoluta-mente el carácter teológico de la exégesis y sin referencia a la Tradición viva de la Iglesia, entendida esta como una de las claves hermenéuticas, capaz de ofrecer garantía objetiva a la interpretación bíblica.

El entonces Cardenal, afirmaba categóricamente que "el hiato entre exégesis y teología es, al presente, total y que la Escritura se ha convertido por ello en una palabra del pasado que cada quien se esfuerza a su modo en transportar al presente, sin que pueda confiar demasiado en la balsa en la que se ha embarcado. La fe se reduce entonces a una suerte de filosofía de vida que cada cual, en la medida de sus posibilidades, busca extraer de la Biblia".

Han pasado más de dos décadas y las consecuencias de esta crisis exegética parecen haber cambiado muy poco, todo lo contrario, se han agudizado con serias implicaciones tanto para la pastoral como para la espiritualidad cristiana. Benedicto XVI las enumera en su Verbum Domini35:

a) Ante todo, si la actividad exegética se reduce únicamente al primer nivel, la Escritura misma se convierte sólo en un texto del pasado: 'Se pueden extraer de él consecuencias morales, se puede aprender la historia, pero el libro como tal habla sólo del pasado y la exégesis ya no es realmente teológica, sino que se convierte en pura historiografía, en historia de la literatura.

b) La falta de una hermenéutica de la fe con relación a la Escritura no se configura únicamente en los términos de una ausencia; es sustituida por otra hermenéutica, una hermenéutica seculariza, cuya clave fundamental es la convicción de que Dios no aparece en la historia humana. Según esta hermenéutica, cuando parece que hay un elemento divino, hay que explicarlo de otro modo y reducir todo al elemento humano. Por consiguiente, se proponen interpretaciones que niegan la historicidad de los elementos divinos (...).

c) Una postura como esta, no hace 
más que producir daño en la vida de la Iglesia, extendiendo la duda sobre los misterios fundamentales del cristianismo y su valor histórico (...) La adopción de esta hermenéutica en los estudios teológicos introduce inevitablemente un grave dualismo entre la exégesis, que se apoya únicamente en el primer nivel, y a teología, que se deja a merced de una espiritualización del sentido de las Escrituras no respetuosa del carácter histórico de la revelación. d)Todo esto resulta negativo también para la vida espiritual y la actividad pastoral: 'La consecuencia de la ausencia del segundo nivel metodológico es la creación de una profunda brecha entre exégesis científica y lectio divina. Precisamente de aquí surge a veces cierta perplejidad también en la preparación de las homilías' (...)

e) En definitiva, 'cuando la exégesis no es teología, la Escritura no puede ser el alma de la teología y, viceversa, cuando la teología no es esencialmente interpretación de la Escritura en la Iglesia, esta teología ya no tiene fundamento'.

Desde este panorama bíblico muy incierto, surge la siguiente interrogante, ¿cómo afrontar las consecuencias de esta dicotomía interpretativa provocada por la exégesis positivista y una hermenéutica secularizada a la hora de interactuar con los textos bíblicos? Sólo parece haber una respuesta: recomponer la unidad "perdida" de los dos niveles metodológicos de la exégesis, de modo que sea crítica y teológica a la vez. Esta recomposición debe estar en concomitancia decisiva con la validación intersubjetiva de los criterios de interpretación bíblica que fueron definidos por la Dei Verbum 12, los cuales resumo a continuación: Para el nivel históricocrítico hay que: $1^{\circ}$ atender a las formas o géneros literarios; $2^{\circ}$ estudiar el contexto histórico (cultural, religioso, etc.); y $3^{\circ}$ examinar la situación vital o Sitzimleben (la circunstancia y exigencia de un modo particular de responder a una situación específica). Y para el nivel hermenéutico se debe:

$1^{\circ}$ considerar la unidad cristológica de toda la Escritura; $2^{\circ}$ tener presente la Tradición viva de toda la Iglesia; $3^{\circ}$ observar la analogía de la fe (o sea, la correlación interna y coherente de la fe) $y$, finalmente, $4^{\circ}$ Leerla con el mismo Espíritu con que fue escrita.

Esta recomposición de la exégesis teológica implica también revalidar el método histórico-crítico, sin dejar de plantear algunas autocríticas al mismo. Asimismo, exige que nos acerquemos a la Sagrada Escritura según lo que ella realmente es, Palabra de Dios que se nos comunica a través de palabras humanas, leyéndola e interpretándola, como se ha dicho. con el mismo Espíritu con que fue escrita, teniendo en cuenta que todo proceso de interpretación bíblica auténtico no es sólo intelectual sino también vital, lo cual reclama una total implicación en la vida eclesial, en cuanto vida “según el Espíritu” (Gál 5, 16) (cf. VD 38). 


\section{Necesidad pero no suficiencia del método histórico-crítico}

En su última obra teológica sobre Jesús de Nazaret, especialmente en el prólogo de su primer volumen (2007), Benedicto XVI termina haciendo suya la afirmación de uno de los más grandes exegetas católicos contemporáneos, Rudolf Schnackengurg, cuando concluye "de que mediante los esfuerzos de la investigación con métodos históricos-críticos no se logra, o se logra de modo insuficiente, una visión fiable de la figura histórica de Jesús de Nazaret, pues el esfuerzo de la investigación exegética, por identificar estas tradiciones y llevarlas a lo históricamente digno de crédito, nos somete a una discusión continua de la historia de las tradiciones y de las redacciones que nunca se acaba". No obstante esto, se subraya que "el método histórico, por la naturaleza intrínseca de la teología y de la $\mathrm{fe}$, es y sigue siendo una dimensión del trabajo exegético a la que no se puede renunciar".

Esto mismo fue abordado por el documento antes citado de la PCB cuando sostuvo que el método históricocrítico "se restringe a la búsqueda del sentido del texto búblico en las circunstancias históricas de su producción, y no se interesa por las otras posibilidades de sentido que se manifiestan en el curso de las épocas posteriores de la revelación bíblica y de la historia de la Iglesia". Sin embargo, también se dice que este método ha contribuido a la producción de obras de exégesis y de teología bíblica de gran valor (cf. IBI I, A, 4).
Últimamente, la Verbum Domini también ha reconocido los frutos innegables de la investigación históricocrítica moderna. Pero ha advertido a su vez que no sólo la exégesis actual debe trabajar a un gran nivel en cuanto se refiere a la metodología histórico-crítica, integrando sus resultados, sino que es preciso exigir un estudio análogo de la dimensión teológica de los textos bíblicos, con el fin de que progrese la profundización, de acuerdo a los criterios teológicos señalados por la Constitución dogmática Dei Verbum" (cf. VD 34).

Esta conciencia eclesial sobre las ventajas limitadas del método exegético reclama, por un lado, que las conjeturas y contrastaciones consideren los criterios objetivos de interpretación y busquen realmente fijar el sentido literal de los textos bíblicos, es decir, lo que querían decir los autores (hagiógrafos) a sus contemporáneos y, por otro lado, que la hermenéutica teológica desarrolle el sentido espiritual, es decir, lo que el mismo texto nos dice hoy a nosotros en un contexto distinto y en un lenguaje comprensible al hombre moderno, pero considerando siempre la unidad global y articulada de toda la Sagrada Escritura.

\section{El sentido literal y espiritual}

Como he señalado, el objetivo de la exégesis crítica consiste en determinar el sentido literal (no literalista, el cual es propio del fundamentalista) de los textos bíblicos, el mismo que está expresado por los autores humanos inspirados por el Espíritu de Dios en un contexto originario específico, y siendo el sentido literal el fruto de la inspiración, tal 
sentido es también querido por Dios, autor principal. Así, al sentido literal sólo se lo puede discernir por un análisis preciso del texto, situado en su contexto literario e histórico. De ahí que los exegetas busquen definir el sentido literal bíblico con la mayor exactitud posible, para lo cual deben estudiar los géneros literarios antiguos.

Sobre este particular, Arens (1997) señala que cuando sabemos diferenciar los géneros literarios podemos saber también cuál es su propósito, pero cuando esto no se da, tendemos instintivamente a pensar que tal género debe ser semejante a alguno que sí conocemos. En consecuencia, pensamos que el mensaje (y el propósito) del autor bíblico debe ser tal o cual cuando en realidad es otro. Así, por ejemplo, el hecho de no conocer el género apocalíptico (pues no es de los empleados hoy), conduce a pensar que se trata del género de vaticinios o anuncios futuristas que $\mathrm{CO}^{-}$ nocemos por el género moderno de ciencia ficción, y en consecuencia se piensa que el propósito del Apocalipsis es el de informar acerca de los acontecimientos que sucederán antes del fin del mundo.

El sentido literal tiene un peligro latente, la tendencia a limitarlo con circunstancias históricas precisas. Esto quizá porque todo escrito tiene la capacidad de ser situado en nuevas circunstancias que lo iluminan de modo diferente aña-diendo a su sentido nuevas determinaciones. Pero de esto no se sigue que se pueda atribuir a un texto bíblico cualquier sentido, interpretándolo de modo subjetivo (cf. IBI, II, 1 y 2).
En cuanto al sentido espiritual que, a veces se identifica y otras se distingue del sentido literal, pues tiene su relación y base indispensable en este, se lo puede captar sólo si se lo lee bajo la influencia del Espíritu Santo y los demás criterios antes mencionados. Este sentido espiritual no debe ser confundido con interpretaciones subjetivas dictadas por la imaginación o la especulación intelectual, pues dicho sentido proviene de la relación del texto con datos reales que no le son extraños.

La PCB nos refiere que cuando una lectura espiritual, hecha en comunidad o individualmente, no descubre un sentido espiritual auténtico es porque no se mantiene en la perspectiva de la relación íntima que existe entre sentido literal y sentido espiritual (cf. IBI, II, 1 y 2).

\section{Características y etapas del método histórico-crítico}

El método histórico-crítico es un método indispensable para lograr el sentido literal de los textos bíblicos, ya que la Sagrada Escritura, en cuanto 'Palabra de Dios en lenguaje humano', ha sido compuesta por autores humanos en todas sus partes y todas sus fuentes, su justa comprensión no solamente la admite como legítima, sino que requiere la utilización de este método.

Este nivel metodológico se justifica en última instancia porque la fe cristiana es constitutivamente histórica, y puesto que la Sagrada Escritura es un testigo escrito de ese hecho histórico no podemos acercarnos a ella más que por medios que estudian la historia y la literatura. En realidad, no hay revelación 
de Dios sin historia. Benedicto XVI subraya que "para la visión católica de la Sagrada Escritura, la atención a estos métodos es imprescindible y va unida al realismo de la encarnación" (El Logos se hizo historia)... En efecto, "la historia de la salvación no es una mitología, sino una verdadera historia, y por tanto, hay que estudiarla con los métodos de la investigación histórica seria" (VD 32).

Si dejamos de lado la historia, la fe bíblica quedaría desfigurada y transformada en otra religión. "Así pues, si la historia, lo fáctico, forma parte esencial de la fe cristiana en este sentido, ésta debe afrontar el método histórico. $\mathrm{La}$ fe misma lo exige" (Benedicto XVI, 2007, 11).

Presento ahora las características de este método exegético y sus respectivas etapas que buscan alcanzar el sentido literal, sabiendo que actualmente se proponen otros métodos o acercamientos no menos valiosos. Para ello me basaré, una vez más, en lo ampliamente desarrollado por el documento de la PCB que parte de la crítica textual hasta el estudio crítico de la redacción (cf. IBI, I, A, 2-4).

\section{Características:}

En primer lugar, es un método crítico porque procura dilucidar los procesos históricos de producción del texto bíblico, pero que son procesos diacrónicos a veces complicados y de larga duración en diferentes etapas, cuyos destinatarios, oyentes y lectores, se encontraban en situaciones espaciotemporales diferentes. En segundo lugar, es un método crítico porque opera con la ayuda de criterios científicos tan objetivos como sea posible en cada uno de sus pasos o etapas, tratando de hacer accesible al lector moderno el sentido literal de los textos bíblicos difíciles de captar. Finalmente, es un método analítico porque estudia al texto bíblico como cualquier otro texto de la antigüedad, y lo comenta como lenguaje humano. Lo que le permite al exegeta, sobre todo cuando hace el estudio crítico de la redacción de los textos, captar mejor el contenido de la revelación divina.

Pasos o etapas:

$1^{\circ}$ Crítica textual, se apoya en testimonios de manuscritos más antiguos (papiros, traducciones, etc.) buscando establecer un texto bíblico tan próximo al texto original como sea posible. Con los aportes de la filología histórica se somete a un análisis lingüístico (morfología y sintaxis) y semántico.

$2^{\circ}$ Crítica literaria, discierne el comienzo y el final de las unidades textuales, grandes y pequeñas, y verifica la coherencia interna de los textos. Demuestra la existencia de duplicados, de divergencias irreconciliables y de otros indicios que indican el carácter compuesto de algunos textos, que son divididos en pequeñas unidades, de las cuales se estudia su posible pertenencia a fuentes diversas.

$3^{\circ}$ Crítica de las formas, procura determinar los géneros literarios, su ambiente de origen, sus rasgos específicos y su evolución. 
$4^{\circ}$ Crítica de las tradiciones, sitúa los textos en las corrientes de tradición, de los cuales procura precisar la evolución en el curso de la historia.

$5^{\circ}$ Crítica de la redacción, estudia las modificaciones que los textos han sufrido antes de quedar fijados en su estadio final y analiza ese estadio final, esforzándose por discernir las orientaciones que le son propias.

Si observamos las primeras cuatro etapas del método, podemos caer en la cuenta de que se trata de explicar el origen y la evolución del texto bíblico desde una perspectiva diacrónica, para luego introducir en la quinta etapa, una conclusión de tipo sincrónico. Al respecto, se sostiene que "se debe reconocer que la inclusión en el método ( $5^{\circ}$ etapa) de un análisis sincrónico de los textos es legítima, porque es el texto en su estadio final, y no una redacción anterior, el que es expresión de la Palabra de Dios. Pero el estudio diacrónico continúa siendo indispensable para captar el dinamismo histórico que anima la Sagrada Escritura, y para manifestar su rica complejidad".

Aquí tenemos otra dificultad para nuestro método en cuestión, el peligro del historicismo diacrónico (objetivismo) que deje de lado la perspectiva sincrónica (sentido espiritual), o a la inversa, como afirmar sólo lo sincrónico (cayendo en un subjetivismo peligroso) sin referente diacrónico (sentido literal). Por tanto, ni solamente sincrónico (teológico) ni puramente diacrónico (histórico), ya que la relación armónica entre lo diacrónico y lo sincrónico es lo que garantiza la unidad metodológica de la interpretación bíblica. Una vez más, no puede haber teología sin sustento histórico, aunque ella no se reduce a lo meramente histórico.

A modo de autocrítica, pienso que se debería someter a revisión crítica los propios resultados del método exegético siguiendo la misma perspectiva diacrónica, sobre todo, de algunos datos exegéticos que se refieren al Antiguo Testamento (AT)y al Nuevo Testamento (NT). Sobre este punto, Ratzinger planteaba en su Conferencia una crítica de la crítica, respecto precisamente de una exégesis positivista: "Una autocrítica del método histórico debería comenzar por una lectura diacrónica de sus propios resultados; debería, por tanto, renunciar a la apariencia de una certeza equiparable a la de las ciencias de la naturaleza, con la cual hasta ahora son generalmente presentadas sus interpretaciones".

Este punto me sirve para cuestionar la pretendida objetividad con la que se movería el exegeta, lo que no siempre es posible. El estudioso de la Biblia es un hijo de su tiempo y como tal tiene una serie de prejuicios o pre-comprensiones (muchas veces inconsciente) que condicionan su investigación. Él no está libre de ideologías o cosmovisiones dominantes. En realidad, como bien decía Gadamer en su célebre escrito Verdad y Método (1960), las precomprensiones, que marcan nuestra comprensión, provienen de la tradición que nos sostiene. $\mathrm{Y}$ esta tradición consiste en un conjunto de datos históricos y culturales que constituyen nuestro contexto vital, nuestro horizonte de comprensión. De ahí que no sorprenda la radical afirmación de Ratzinger en su Conferencia citada: "el 
debate acerca de la exégesis moderna no es en su núcleo un debate entre historiadores, sino un debate filosófico".

Queda claro, entonces que, en tanto ciencia humana, la exégesis y sus resultados están profundamente condicionados por la posición que toma el investigador ante el objeto. No se puede pretender la misma objetividad de las ciencias naturales. $\mathrm{Y}$ si esto resulta evidente en el caso del historiador aún lo es más en el caso del exegeta. Y para la exégesis bíblica, la naturaleza de su objeto es el acontecimiento de la revelación de Dios en la historia tal y como es testimoniado en la Escritura, lo cual requiere una toma de posición que condicionará en mayor o menor medida su respectiva comprensión.

Aplicando esta acotación a los autores bíblicos, se puede contrastar con muy poca dificultad que ellos no hablan de sí mismos o para sí mismos. Como dice Benedicto XVI (2007), ellos hablan a partir de una historia común en la que están inmersos. El autor bíblico no habla como sujeto privado, encerrado en sí mismo. Habla en una comunidad viva y por tanto en un movimiento histórico vivo donde actúa la fuerza del Espíritu. En realidad, la Escritura ha surgido en y del sujeto vivo del Pueblo de Dios en camino y vive en él. Este pueblo no es autosuficiente sino que se sabe guiado y llamado por Dios mismo que, en el fondo es quien habla a través de los hombres y su humanidad. El pueblo de Dios, la Iglesia, es el sujeto vivo de la Escritura; en él, las palabras de la Biblia son siempre una presencia.

Termino mi intervención citando el
Mensaje Final del Sínodo de los Obispos sobre la Palabra de Dios (2008), donde se decía que "cada lector de las Sagradas Escrituras, incluso el más sencillo, debe tener un conocimiento proporcionado del texto sagrado recordando que la Palabra está revestida de palabras concretas a las que se pliega y adapta para ser audible y comprensible a la humanidad. Éste es un compromiso necesario: si se lo excluye, se podría caer en el fundamentalismo que prácticamente niega la encarnación de la Palabra divina en la historia, no reconoce que esa Palabra se expresa en la Biblia según un lenguaje humano, que tiene que ser descifrado, estudiado y comprendido, e ignora que la inspiración divina no ha borrado la identidad histórica y la personalidad propia de los autores humanos. Sin embargo, la Biblia también es Verbo eterno y divino y por este motivo exige otra comprensión, dada por el Espíritu Santo que devela la dimensión trascendente de la Palabra divina, presente en las palabras humanas".

\section{Conclusiones}

La recomposición de la unidad de los dos niveles metodológicos de la interpretación (investigación histórica y hermenéutica de la fe) es aún un largo camino que debemos recorrer con sentido de fe eclesial, promoviendo una exégesis no sólo crítica o histórica sino también teológica, que considere la correcta relación entre razón y fe.

Para ello, es imprescindible considerar los criterios decisivos de la interpretación bíblica, pues de no ser así, caeríamos necesariamente en la lamen- 
table separación, contraposición o yuxtaposición entre exégesis y teología, agudizándose más los reduccionismos epistemológicos que de hecho nos impiden comprender el evento de la revelación de Dios mediante su Palabra que se nos transmite en la Tradición viva y en la Sagrada Escritura.

Aunque reconocemos el valor del método histórico-crítico, es urgente plantear una autocrítica desde él mismo, que trascienda lo puramente procedimental, revise sus resultados y discierna los historicismos y positivismos que reducen la exégesis sólo a la perspectiva diacrónica, pues a pesar de haber producido excelentes resultados, no se ha fecundado realmente a la teología, menos aún, ha contribuido a comprender la Biblia como Palabra de Dios.

Este método crítico, al no ser fin en sí mismo ni exclusivo, no debe perder de vista su función vital en la Iglesia y en el mundo, como es contribuir a una transmisión más auténtica de la Palabra de Dios expresada en lenguaje humano, pues "sólo donde se aplican los dos ni- veles metodológicos, el histórico-crítico y el teológico, se puede hablar de una exégesis teológica, de una exégesis adecuada a este libro" (VD 34).

Esto implica también discernir constantemente nuestras propias precomprensiones que se manifiestan en el trabajo exegético, pues estas de hecho impactan en nuestra perspectiva diacrónica y sincrónica, las cuales no se pueden reemplazar, y afectan seriamente el sentido literal y espiritual de los textos bíblicos.

Finalmente, termino citando algo que es recurrente en todos los documentos sobre el tema y que ilumina muy bien nuestro propósito en esta presentación: "En el trabajo de interpretación, los exegetas católicos no deben olvidar nunca que lo que interpretan es la Palabra de Dios. Su tarea no termina con la distinción de las fuentes, la definición de formas o la explicación de los procedimientos literarios. La meta de su trabajo se alcanza cuando aclaran el significado del texto bíblico como Palabra actual de Dios" (IBI III, C, 1; VD 33). 


\section{Referencias}

- Arens, E - Díaz Mateos, M. (1997) ¿Interpretación de la Biblia en crisis? Lima: CEP.

- Benedicto XVI (2010) Exhortación Apostólica "Verbum Domini", sobre la Palabra de Dios en la Vida y en la Misión de la Iglesia. Roma: Ediciones Vaticano.

- Benedicto XVI (2007) Jesús de Nazareth. Desde el Bautismo hasta la Transfiguración. Vol. I, Madrid: Planeta

- Caballero, José María (1994) Hermenéutica y Biblia. Navarra: Verbo Divino.

- Carbajosa, Ignacio (2011) De la fe nace la exégesis. La interpretación de la Escritura a la luz de la historia de la investigación sobre el Antiguo Testamento. Navarra, Verbo Divino.

- Constitución Dogmática Dei Verbum, sobre la Revelación Divina (1963). Roma: Ediciones Vaticano.

- Croatto, Severino. (1994) Hermenéutica Bíblica. Buenos
Aires: Lumen.

Gadamer, H. G. (1960) Verdad y Método. Salamanca: Sígueme.

- León XIII (1893) Encíclica Providentissimus Deus, sobre el estudio de la Sagrada Escritura. Roma: Ediciones Vaticano.

- Levoratti, A. (2005) Cómo Interpretar la Biblia. En Comentario Bíblico Internacional Católico y Ecuménico para el siglo XXI. Navarra: Verbo Divino.

- Pío XII (1943) Encíclica Divino AfflanteSpiritu, sobre los estudios bíblicos. Roma: Ediciones Vaticano.

- Pontificia Comisión Bíblica (1993) La Interpretación de la Biblia en la Iglesia. Roma: Ediciones Vaticano.

Sínodo de los Obispos (2008) Sobre la Palabra de Dios. Roma: Ediciones Vaticano.

Ratzinger, J. (1987) La Interpretación bíblica en crisis. Problemas del fundamento y la orientación de la exégesis hoy. Vida y Espiritualidad: Lima. 